\title{
Effects of Substance Use Disorder on Women's Roles and Occupational Participation
}

\author{
*Humayra Rawat; B. Occ Ther. (UKZN). http://orcid.org/0000-000 I-909 I-8488 \\ Occupational Therapist, Wagner Occupational Therapy Inc., East London, Eastern Cape.
}

\author{
Stacey Lisa Petzer; B.Occ Ther. (UKZN). http://orcid.org/0000-0002-I586-3453
}

Occupational Therapist, Hillingdon Hospital, Uxbridge, England.

\section{Thavanesi Gurayah; B.Occ.Ther. (UKZN); M.OT (UKZN). http://orcid.org/0000-000 I-9005-6355}

Lecturer, Discipline of Occupational Therapy, School of Health Sciences, University of KwaZulu-Natal.

Introduction: Literature regarding the psychosocial sequelae of substance abuse is largely androcentric and limited regarding the negative effects on women's functioning. This study aims to explore the effects of substance abuse on the roles and occupations of women. Methods: This phenomenological qualitative study utilized a purposive snowball sampling strategy to recruit women with a history of substance abuse. Semi-structured interviews were conducted with six participants.

Findings: Six main themes emerged. The themes alluded to the participants' neglect of self-care, sleep, and IADL (instrumental activities of daily living) responsibilities. They were socially isolated, and their work lives suffered because of their substance abuse. Conclusion: The study concluded that substance abuse negatively affects a woman's ability to engage in her daily occupations and unique roles. Inadequate self-care, debt, neglect of child-rearing roles and work underperformance were some consequences of their abuse. However, it was found that the adoption of new roles associated with advocacy and altruism facilitated the recovery process. The findings can be used to create gender specific interventions for women with substance use disorders.

Key words: substance abuse, women, areas of occupation, occupational disruption.

\section{INTRODUCTION}

Substance abuse is a global mental health issue that has serious health and social sequelae. The abuse of substances is considered primarily an issue amongst males and research has been largely androcentric'. However, in recent years there has been an increase in the amount of research involving female populations as the health sector continues to realise the importance of establishing malefemale differences in this area of study ${ }^{2}$. A South African study in 2018 found that substance abuse in men was significantly higher than in women, who were at a higher risk if they had comorbid anxiety or depression ${ }^{3}$.

The differences between men and women who abuse substances are significant. The National Institute on Drug Abuse (NIDA) ${ }^{4}$ reported that women experience substance use differently than men due to biological reasons such as hormones, menstruation, pregnancy, menopause, and metabolism. A phenomenon known as 'telescoping' explains how metabolic differences in women lead to accelerated progression from the initiation of substance use to the onset of dependence ${ }^{2,5}$, which adds impetus to this research. Women were also found to be more vulnerable to relapse, experience greater cravings and have unique motives for using substances, including controlling weight, coping with pain or self-medicating for mental problems 4 . According to the Substance Abuse and Mental Health Services Administration ${ }^{6}$, women enter treatment with more complex medical, social, behavioural and/or psychological issues. NIDA ${ }^{4}$ states that women may also experience substance use differently than men because of culturally defined roles and occupations. Women juggle multiple roles, often leading to role overload and strain ${ }^{7}$. This forms part of the need for the study as these factors can lead to occupational imbalance and reduced role fulfilment. Substance abuse can also result in the disruption of meaningful occupations, such as education, parenting, and work $^{8}$.

The amount of literature available on women with substance use disorders is increasing, especially with regards to the biological variations between male and female substance abusers ${ }^{2,9}$. However, there is little research available in the occupational therapy profession regarding the effects of substance abuse on the roles and occupations of women specifically. Therefore, existing psychosocial interventions in substance abuse are largely male-specific and fail to cater for females, resulting in women disengaging from therapy ${ }^{10}$. This study aims to close the gap in the research by exploring the effects of substance abuse on the roles and occupations of women with substance use disorders.

This study will facilitate the development of gender-specific interventions that considers the special needs of women ${ }^{10}$. By acknowledging that the background characteristics, substance abuse patterns, and personal backgrounds of female substance users differ from those of males, treatment programmes can be designed specifically to address women's substance abuse-related problems, special needs, and barriers to treatment. Such research can be used 
to inform the training of occupational therapy students, as well as qualified therapists. It will also be beneficial in adding to the literature on occupational science, as well as adding to the knowledge in the field of women with substance use disorders.

\section{LITERATURE REVIEW}

Substance use disorder (SUD) incorporates both substance abuse and substance dependence. It occurs when the recurrent use of illicit substances causes clinical and functional impairment, such as health problems, disability, and failure to meet responsibilities" ${ }^{\prime}$. A diagnosis is made using evidence of impaired control, social impairment, and risky use.

Much of the comparative literature pertaining to substance disorders acknowledge the differences in biology, co-morbidities, treatment considerations and social issues in both genders. Research indicates that women take less time to progress from substance use to dependence and have a higher rate of relapse ${ }^{9,12}$. Moreover, women are more likely to experience the medical and physical sequelae associated with the abuse of drugs and alcohol ${ }^{13}$. Studies exploring the societal differences of addiction concluded that men presented with more career-based difficulties whilst women were found to experience greater family and social impairment ${ }^{13}$. Research indicates that more female substance users are divorced or separated than men ${ }^{14}$, which has implications for their role functions.

Women are expected to have a healthy balance between roles and occupations to live balanced lifestyles ${ }^{15}$. When women are overburdened with multiple roles and occupational demands, it is common for them to experience strain and role overload, leading them to use substances as a coping mechanism, thus perpetuating a vicious cycle ${ }^{16-18}$.

Substance abuse can also result in failure to fulfil role responsibilities at work, school, or home. It has negative consequences on social participation and recreational activities such that individuals may withdraw from family activities and hobbies. Activities of daily living for individuals with substance use disorder may revolve around the use of illicit substances, resulting in occupational imbalance ${ }^{|9-2|}$. Important instrumental activities of daily living such as shopping, food preparation, home maintenance and care of others are forgotten $^{20}$. Mothers who abuse substances lose contact with their children as they are declared unfit to take care of their offspring ${ }^{22}$.

When under the influence of substances, women have an increased likelihood of engaging in high-risk sexual activities ${ }^{23}$. Risk taking is associated with the non-use of condoms, and an increase in the number of sexual partners, increasing the probability of becoming pregnant and contracting sexually transmitted infections (STIs) ${ }^{24}$, ${ }^{25}$. In South Africa, unsafe sex resulting in STIs accounted for $31.5 \%$ of the total disability-adjusted life years in the general population ${ }^{26}$. In a study that assessed the association between alcohol abuse, high risk sexual behaviours and sexually transmitted diseases in women in Northern Tanzania, it was found that alcohol abuse was affiliated with STI's, through its association with multiple sexual partners ${ }^{27}$. This shows the linkage between substance abuse, risky sexual behaviours, and sexually transmitted diseases, specifically in women. We can anticipate that the consequences of obtaining sexually transmitted diseases such as HIV will reduce a women's ability to fulfil her roles, particularly as the disease progresses. Women who drink excessively also have an increased risk of exposure to sexual and physical abuse from partners ${ }^{23}$. Conversely, women who experienced physical or sexual violence were more likely to abuse substances as a coping mechanism ${ }^{23}$. Violence against women may perpetuate their mental illnesses, further increasing the possibility of substance abuse.

The abuse of substances during pregnancy is also documented in the literature. The continued use of substances by women during pregnancy is seen as a maladaptive coping mechanism to deal with their daily socio-political challenges, which may include extreme poverty, high crime rates, and high morbidity and mortality rates due to disease and violence ${ }^{26,28}$. The continued use of substances during pregnancy may predispose the child to foetal alcohol syndrome, developmental delays, premature birth, low birth weight, slowed growth, and various physical, emotional, behavioural, and cognitive problems ${ }^{29,30}$. When a child is born with a physical and/ or mental disorder, we can anticipate that the burden of caring for the mother of this child will be increased.

Research shows children of parents who abuse illicit substances have an increased likelihood of being maltreated or neglected, as parents are unable to fulfil parental roles ${ }^{31-33}$. Parents with substance use disorder may be unable to regulate their emotions and levels of stress, therefore their behaviour may become impulsive and highly reactive leading to physical abuse of the child ${ }^{34}$. Conversely children who are separated from parents or who have inconsistent care givers may have attachment difficulties which can interfere with the child's emotional development. This can result in the child turning to substances as a coping mechanism later in life ${ }^{33}$.

In South Africa specifically, there are many socio-economic factors which impact negatively on the living conditions of the population, especially marginalized groups consisting mainly of black and coloured women ${ }^{23,28}$. With the low socio-economic status of these women, they become trapped in the cycle of poverty. Being a woman of colour, having a low education level, low income, living in substandard conditions in high crime neighbourhoods, and not having the support of a partner, is said to increase a woman's experience of stress ${ }^{23}$. In a study of 898 women, it was found that those living in substandard living conditions had a higher risk of abusing substances, experiencing physical and sexual abuse from partners, and contracting $\mathrm{HIV}^{23}$. It was also noted that the cultural norms and meanings could affect the use of substances ${ }^{35}$, if the attitude to alcohol is permissive or prohibited. Cultural norms are said to be the shared perceptions and rules of a particular social group $^{36}$. For example, alcohol is taboo in the Islamic culture ${ }^{37}$, and there may be lower rates of alcoholism among women in this community as a result. This may be a barrier to individuals, including women, seeking help for their addiction, as it is highly stigmatized.

It was found that the use of illicit substances may be a learnt or modelled behaviour by women ${ }^{28}$. Women drink to help them deal with their harsh realities, escape their problems to relax, overcome self-esteem issues and boredom, and deal with depression, therefore making drinking an "entrenched form of occupational engagement" 28 . This excessive drinking impacted negatively on their personal and social well-being, as well as their development as individuals, and as a part of their respective social groups ${ }^{28}$. Therefore, to cope with all the factors previously mentioned, women may increasingly turn to substance use when diagnosed with a mental illness.

Women's experiences of daily life stresses, role strain and overload, socio-political and socio-economic challenges, disease, and violence can be triggers for the use of substances. However, there is a gap in the research, where very little to no information was found on the direct effects of substance abuse on the roles and occupations of women. Thus, research into the effects of substance use on the roles and occupations of women would be helpful in 
the development of more suitable interventions and programmes for women in recovery.

\section{METHODOLOGY}

\section{Aim of the Study}

The aim of the study was to understand the effects of substance use disorder on women's roles and occupational participation.

\section{Study Design}

A qualitative design was selected as it allowed the researchers to discover the subjective experiences of the women. A phenomenological approach was used as it is a flexible approach that focuses on several individuals' lived experiences of the phenomenon under study $^{38}$. The study design allowed the researchers to modify the research process; revisions were made along the way as new experiences emerged, where the researchers were able to familiarize the line of questioning and accommodate new patterns and themes as they emerged.

\section{Study Context}

The research was conducted within the eThekwini district. Participants were initially recruited from the Marianridge community via the Marianridge Coordinating Committee (MCC) as the researchers were final year occupational therapy students placed here for community fieldwork and were familiar with the substance abuse prevalence in the community. Other participants were residents to the eThekwini area and were of varying economic and political backgrounds. None of the participants were familiar to the students.

\section{Participants}

The study sample consisted of six women who had a history of substance use disorders. All women had to have received partial or holistic social or medical intervention for their addiction to be eligible for the study. This was important as the researchers acknowledged that women who had sought treatment would have greater insight into the effects of their substance abuse, as compared to women who sought no intervention at all. Whilst the researchers aimed to achieve a diverse sample with women from all races, ethnicities, and stages of adulthood in the eThekwini district, they were only able to recruit participants who were Indian and Coloured between the ages of $3|-5|$. Most of the participants were either Hindu or Christian. It was difficult to recruit participants for the study due to the stigma women with substance abuse face. Despite the small number of participants, data saturation was reached. Table I below provides further information about the six study participants.

\section{Recruitment Process}

Purposive and snowball sampling were used. Snowball sampling consisted of identifying respondents who then referred researchers on to others that met the inclusion criteria of the study. The initial two participants were recruited from the MCC where the students had conducted their fieldwork. Through these participants, four other prospective participants were recruited within the eThekwini district. Since prospective participants were found through mutual acquaintances with similar social circumstances, the natural barriers of stigma, which normally would prevent these individuals from taking part, were broken down.

\section{Data Collection}

Data was collected using six semi-structured individual interviews which were audio taped with permission. The semi-structured interviews consisted of several key questions and prompts guided by the Occupational Therapy Practice Framework's ${ }^{39}$ defined areas of occupation and roles (see Appendix I: Interview Schedule). The questions were carefully formulated to be open ended, thereby ensuring that participants could express their views without being influenced by the researchers' own opinions. The semi-structured interviews occurred in the participants' home environment or a place of their choice, providing a setting whereby they were most comfortable. Each interview was conducted by the four researchers for a duration of 60-90 minutes ensuring adequate time to collect detailed information. Prior to commencing the semi-structured interviews, participants were given an information sheet regarding the purpose of the research.

Table I. Demographic description of participants

\begin{tabular}{|c|c|c|c|c|c|c|c|}
\hline $\begin{array}{c}\text { Participant } \\
\text { (Pseudonyms) }\end{array}$ & Age & Race & $\begin{array}{l}\text { Marital } \\
\text { Status }\end{array}$ & Children & $\begin{array}{l}\text { Level of } \\
\text { Education }\end{array}$ & Employment & $\begin{array}{c}\text { Type of } \\
\text { substance }\end{array}$ \\
\hline Meera & 44 & Indian & Divorced & 1 & $\begin{array}{c}\text { Post } \\
\text { Graduate }\end{array}$ & Employed & $\begin{array}{l}\text { Alcohol } \\
\text { Cocaine } \\
\text { Prescription } \\
\text { medication }\end{array}$ \\
\hline Leeane & 51 & Coloured & Widowed & 3 & Grade 8 & Uরelmptefed & Alcohol \\
\hline Heena & 44 & Indian & Separated & 2 & Gragstate & Unemployed & $\begin{array}{c}\text { Prescription } \\
\text { medication }\end{array}$ \\
\hline Madhavi & 31 & Indian & Divorced & 0 & Gragstate & Unemployed & Alcohol \\
\hline Shanice & 44 & Indian & Divorced & 3 & Grade 12 & empalfoyed & elcsohasy \\
\hline Natalie & 43 & Coloured & Single & 2 & Grade 5 & Unemployed & 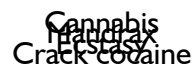 \\
\hline
\end{tabular}




\begin{tabular}{|l|l|}
\hline \multicolumn{1}{|c|}{ THEMES } & \multicolumn{1}{|c|}{ SUBTHEMES } \\
\hline I. Failing to function & $\begin{array}{l}\text { a) Sleeplessness } \\
\text { b Reduced hygiene } \\
\text { c) Sexual functioning }\end{array}$ \\
\hline 2. Relinquishing my roles and responsibilities & $\begin{array}{l}\text { a) Passing the buck } \\
\text { b) Hazardous health behaviours } \\
\text { c) It's all about the money }\end{array}$ \\
\hline 3. Me, myself, and isolation & $\begin{array}{l}\text { a) Isolating myself } \\
\text { b) An embarrassment to the family } \\
\text { c) Judged by others }\end{array}$ \\
\hline 4. Work related issues. & $\begin{array}{l}\text { a) Poor Job performance } \\
\text { b) Unemployment }\end{array}$ \\
\hline 5. Loss of leisure opportunities & a) Leaving leisure behind \\
\hline 6. Life after substance & $\begin{array}{l}\text { a) The role of advocate } \\
\text { b) A spiritual reawakening }\end{array}$ \\
\hline
\end{tabular}

Thereafter, the participants signed a consent form stating their agreement to participate in the semi-structured interviews and for the interviews to be audio recorded.

\section{Data Analysis}

The semi-structured interviews were transcribed verbatim by the researchers using the audio recordings. Pertinent ideas uncovered in the data were coded in a systematic colour coded fashion across the entire data set, collating data relevant to each code. The codes were then collated into sub-themes and all data relevant to each sub theme were gathered. Each transcription was analysed by each of the researchers, to ensure trustworthiness, especially with regards to dependability, confirmability, and credibility. Thematic analysis was done using inductive reasoning. The researchers came together for consensus and to name the themes and subthemes. Sub-themes were checked to ensure they accurately represented the data as previously coded. This ensured that a thematic map of the analysis could be generated. The continued analysis of each sub- theme resulted in concrete themes being identified. Common sub-themes identified across all interviews were then merged to produce six themes. Compelling extract examples were selected and underwent final analysis. The analysis was linked to the research question and literature, therefore producing a scholarly report of the analysis ${ }^{40}$.

\section{Ethics}

Ethical clearance was obtained from the University of Kwazulu-Natal Humanities and Social Sciences Research Ethics Committee in 2018 (Ethical clearance number: HSS/0 199/0 I8H). To gain access to participants within the Mariannridge community, gate keeper permission was sought from the Marrianridge Coordinating Committee (MCC) who led us to our first participants. All participants were asked to sign a consent form once they had been informed about the procedures of the study. They were reassured about confidentiality and that they would not be identified in any publications, as pseudonyms were used.

\section{FINDINGS}

Six themes emerged from the study and are depicted in Table II.

\section{Theme I: Failing to function}

The women neglected their activities of daily living (ADLs). Difficulty falling asleep and maintaining sleep were common amongst the participants. Poor hygiene was noted as they forgot to bath or perform simple grooming tasks due to preoccupations with their addiction. The neglect resulted in poor physical appearance which consequently caused lowered self-esteem. Shanice said: "I went from being a beautiful woman to looking like a hag ... I didn't care if I had a bath, I didn't care about anything."

A change in sexual behaviour was reported as the women either partook in risky sexual activities or had reduced libido. Shanice reported: "There were times when I sold myself for alcohol, when I woke up in hotel rooms and I didn't know how I got there ... I couldn't remember who the guy was, let alone what we did and how we did it."

\section{Theme 2: Relinquishing my roles and responsibilities}

This theme focused on the impact on instrumental activities of daily living (IADLs). Participants neglected their roles as a mothers as they passed on the responsibility of their children to other family members. Meera said: "I would neglect my child a lot, leaving him in the care of my parents." Their addiction impacted on their own health and their children's. Shanice said: "... as the direct result of my drinking, my son has cerebral palsy." And Natalie reported: "I am very sickly now... it did a lot of damage to my body and little bit mentally."

Participants experienced financial hardships. They would sell their belongings, spend their savings, or the last of their money to get the next fix. Leeanne said: "If you have a R20, the money is going on alcohol ... Tomorrow will see it for itself, that's what you're telling yourself."

\section{Theme 3: Me, myself, and isolation}

The women's social participation was limited as they experienced isolation and stigma. It resulted in dysfunctional relationships as Meera reported: "l'd like to think that even people who once were 
my friends were not enjoying my company ... so it was a matter of alienation." The women were considered an embarrassment to their families. Meera stated: "I was like a rotten apple... I would rock up piss drunk, and I think I was just a total embarrassment, I had no relationship with them [family]." The women were treated differently and judged by others. Shanice stated: "A lot of women are ashamed to come and say, 'I have a problem with alcohol' because of the stigma attached to it."

\section{Theme 4: Work related issues}

Poor job performance was reported from all participants as their competence, productivity, attendance, and relationships at work were impacted. Heena explains: "One day my boss was out playing golf. I went into his office behind his desk, pulled the chair aside and fell asleep on his carpet floor." Madhavi explained: "you are unreliable and untrustworthy.... it [the alcohol] made me slow... I had assistants under me, so I used them."

The women also remarked on unemployment. Shanice said: "I was forced to resign from the company I was working for because I had stolen from them, and all the money was used to pay off alcohol debt."

\section{Theme 5: Loss of leisure opportunities}

The women's leisure pursuits were unconstructive during their addiction as they spent their time seeking out substances and using them. Many abandoned the leisure activities they would participate in prior to their addiction. Heena said: "Before substance abuse, I was very active ... but during it, my free time was spent planning how to get a script, how am I going to get out of the house and things like that."

\section{Theme 6: Life after substance use}

The participants found altruism and advocacy to be essential in their recovery process. Meera stated: 'I've gone now and made massive contributions to the world of addiction, the world of HIV... I have taken this experience and used it to give back wherever and whenever I can."

Reconnection to religion and spirituality was also seen as a supportive factor to recovery as seen through Shanice's narrative: "Having this relationship with God now is what has turned my whole life around 360 degrees. He moved the craving of alcohol and drugs from my life."

\section{DISCUSSION}

According to the Occupational Therapy Practice Framework $(\mathrm{OTPF})^{39}, \mathrm{ADL}$ are defined as tasks that are oriented towards taking care of one's own body, such as eating, grooming, bathing and sexual functioning. In this study, the women neglected these basic activities when they were abusing substances. The Diagnostic and Statistical Manual of Mental Disorders (DSM-V) ${ }^{13}$ states that individuals with substance use disorders centre all their basic activities around the attainment and use of their substance of choice. Limited gender specific literature exists directly linking substance use to reduced performance in the aforementioned ADLs. In this research, the participants reported risky sexual behaviours which was associated more with the need to fund their addiction rather than for pleasure. Other studies found similar results where women were noted to engage in sexual activities as a trade for substances ${ }^{23,25}$.

Instrumental activities of daily living are activities which support daily living within the home and community ${ }^{39}$, which were also impacted in this study. The role of being a mother was not fulfilled by any of the participants, and child neglect was prominent. The women expected others to care for their children whilst they continued to abuse substances. Neglect and maltreatment of a child by a parent who is an addict is a common occurrence ${ }^{33,41}$. Some of the participants also reported drinking and drugging during their pregnancies, leading to serious conditions in their children, such as cerebral palsy or other learning difficulties. Substance abuse during pregnancy is known to cause harm to the foetus, even resulting in premature birth and developmental delays ${ }^{33,42}$.

Health maintenance, as an important component of IADL was impacted negatively by the women's substance use. Multiple hospitalizations, low immune systems and increased susceptibility to illness were reported by participants. Literature states women are likely to experience negative health sequelae of addiction, and are more susceptible to organ damage than $\operatorname{men}^{43}$. It is important to note that the women's deteriorating health affected their ability to continue with many of their daily occupations. The relevance of these findings suggests that interventions provided should not only be focused on returning to premorbid functioning, but also adapting to new conditions, which may require chronic treatment and compensatory techniques in areas of occupation.

Social participation is the occupation which supports social engagement in community and family activities, as well as with friends ${ }^{39}$. In this study, the women spoke about the dysfunctional relationships with their families. Many of them reported conflicts, disagreement, non-participation in familial events and periods of non-contact with their relatives. These results are similar to other studies ${ }^{44}$. Research also suggested that substance abuse is associated with considerable burden on the family members ${ }^{45}$. The addiction of one family member can become a burden to the whole family unit, resulting in continuous emotional stress, which interrupts the family bonds ${ }^{46}$. The strain on family relationships had a negative effect on the participants' support systems, as families withdrew their emotional and material support during times of stress.

This study showed an increased negative attitude towards women with substance use disorders, as compared to men. These findings have been mirrored in another study ${ }^{47}$. Family and societal attitudes were intolerant to women with addiction. This was due to societal expectations where a woman's primary roles are seen as wife, mother, caretaker, sexual partner, and nurturer, and when they deviate from these prescribed roles, they face stigma and discrimination'. Some participants were exploited, labelled as addicts, blamed or judged by others, and isolated in social settings. This stigma was identified by the women as an obstacle to seeking treatment. Research confirms that stigma can be a pervasive barrier to recovery, as it generates shame and diminishes a woman's selfesteem and willingness to seek treatment ${ }^{48}$. Results from this study suggest that public mental health programmes need to be expanded to include better information about substance use disorders to reduce stigma towards women with addiction.

In this study, the women reported an impact on their work. Christiansen and Townsend ${ }^{49}$ describe work as committed occupations with or without financial compensation. Earlier research supported the view that substance abuse was more likely to affect jobs or career paths for men, whereas disruptions for women were seen to have greater social consequences ${ }^{50}$. These views were based on the traditional roles associated with each gender. Thus, women were previously not included in studies regarding substances in relation to work. However, with more women joining the workforce, studies regarding the impact of substance abuse on work occupations have moved towards including females within their sample populations.

High levels of absenteeism, increased amounts of sick days due to health repercussions, impairment in concentration, and overall 
decreased productivity during their period of substance abuse was reported by the participants of this study. Literature provides evidence of the impact of drinking patterns on absenteeism, as well as the concept of presenteeism which is the state of being present at work, but in an impaired state ${ }^{51}$. Alcohol-related presenteeism was associated with poor task performance and concerns for the safety of the worker, colleagues, and clients. The results were mirrored in this study when a participant explained how she exploited her subordinates to decrease her own workload, as she experienced hangovers from her excessive drinking.

The OTPF ${ }^{39}$ defines leisure as a non-obligatory activity that a person is engaged in during time that is not spent working, engaged in self-care, or sleeping. In this study, it emerged that women disengaged from leisure activities during their abuse of substances. They reported how their interest in hobbies, sports and community activities decreased as they became more focused on the procurement of their substance of choice. Hood ${ }^{52}$ found that women's engagement in leisure declined as their lives became increasingly centred on drinking, recovering from drinking, and planning to drink again.

One of the prominent findings from the study centred around was the roles and occupations the women adopted or returned to during their recovery. Recovery is a process of change where individuals improve their health and wellness, live a self-directed life, and attempt to reach their full potential ${ }^{53}$. In this study, the women returned to community roles once they became sober. Some became advocates for substance addiction by counselling others or becoming a sponsor in Alcoholics Anonymous (AA), whilst other participants provided help to physically sick or disabled individuals within the communities. Pagano, Phillips, Stout, Menard and Piliavin ${ }^{54}$ showed that individuals who used alcohol and helped others during treatment were twice as likely to have maintained sobriety one year following treatment, as compared to non-helpers. This is important, given the challenge of engaging alcoholics with community-based resources to withstand the high-risk period of relapse following treatment.

All the participants spoke about the reconnection to their religion and spirituality, as a source of support in their lives after substance abuse. Whilst some spoke about the importance of their reconnection with God, others emphasized the importance of reconnecting with their religious community. Religion and spirituality are not only a buffer from alcohol and substance abuse, but also plays an important role in the recovery process ${ }^{55}$. The studies utilizing AA or 12-step programmes, as either a sampling method or a recovery programme identified spirituality as a positive factor on recovery ${ }^{56}$.

\section{CONCLUSION}

The study's' findings showed that substance abuse has a pervasive negative influence on all areas of women's life and role functions. It confirmed that women experienced occupational imbalance, alienation, and deprivation due to their substance abuse. Their participation in ADLs, IADLs, sleep, leisure tasks, work occupations and social participation were severely impaired as their addiction took hold.

The neglect of IADLs by the women was prominent, as they failed to care for their children, often passing the responsibility to others. Defiance of their religion, through their addiction and abandonment of their religious observances was also noted. However, later, the women found that spiritual engagement played a vital role in their recovery from addiction. Finances were poorly managed by the women, as abusing substances resulted in major debt, with many still suffering the consequences years later.

Social isolation and alienation stemming from the stigma associated with substance use disorders were common themes experienced by the participants. Their addiction proved to be catalytic in the destruction of many personal and professional relationships, and their ability to fulfil their multiple roles as mother, daughter, partner and friend.

Work occupations were also negatively affected as job duties and responsibilities were disregarded. This resulted in dismissal or sometimes, resignation from their jobs.

Neglect in the above occupations resulted in the women having large amounts of free leisure time. Rather than being used constructively, this time was dedicated towards the acquisition and use of their substance of choice, further compounding occupational imbalance in the women's lives.

Each woman found the recovery from substance use disorder to be a difficult time, however many reported the journey to sobriety helped them establish new positive roles and helping others suffering from addiction.

The findings from this study highlighted the importance of occupational therapy in the rehabilitation of women suffering from substance use disorders, by informing and developing intervention programmes that catered for their specific needs. These programmes should focus on ADL and IADL retraining, including parental skills training, focussing on childcare, home maintenance and meal preparation, social skills training, vocational rehabilitation, financial management and exploring and facilitating sustainable leisure opportunities for women in their communities. It is important for the rehabilitation process to focus on family relationships, which can be facilitated by health professionals whilst the women attempt to reconstruct their lives. Religion and advocacy were powerful tools in the rehabilitation process and need to be enabled during interventions. Research into the effects of women with substance abuse needs to be ongoing with different communities and cultures, and in various contexts, which will help destigmatize the condition further.

\section{ACKNOWLEDGEMENTS}

The authors wish to acknowledge Bongiwe Zulu and Nelisiwe Mabuyakhulu for their contributions towards this study as undergrad researchers. Furthermore, the authors would like to express their gratitude to the women who participated in the research study, without whom this research would not have been possible.

\section{LIMITATIONS}

Snowball sampling possibly contributed to a small sample that was not as representative as initially hoped. This limits the transferability of the study as only Indian and Coloured women participated in this study who were in middle adulthood. The roles found in this stage would be different to those in early or late adulthood however these could not be explored, particularly the impact of substance abuse on student and educational roles. Future studies should aim for maximum variation sampling techniques which will increase the generalizability of the findings and provide information about substances effect on women's roles across the lifespan.

\section{ROLE OF AUTHORS}

HR and SLP were fourth year Occupational Therapy Students at the School of Health Sciences, University of KwaZulu-Natal at the time of the study. They compiled the research proposal, applied 
for and got ethical clearance \& gatekeepers' permission, developed the research questionnaire, interviewed participants, transcribed the audio recordings of interview, did the data analysis, compilation of research dissertation and were involved with the writing of the journal article. TG was their research supervisor at the School of Health Sciences, University of KwaZulu-Natal and provided conceptual writing assistance for the journal article.

\section{APPENDIX I: INTERVIEW SCHEDULE}

\section{Introductory Questions}

I. How did your substance abuse begin?

2. How did the substance abuse effect your life at the time?

3. How did substance use affect your life before rehab?

4. How is your history of substance use affecting your life now, after rehab/coming to the end of your rehabilitation programme?

\section{Roles \& Occupations}

I. What were some of your roles prior to attending rehabilitation?

2. How did substance abuse affect your ability to fulfil these roles?

3. What residual impact has there been on your ability to fulfil your roles now after taking substances?

4. Describe your daily routine when you used substances. Start from when you would wake up to when you went to sleep.

\section{Activities of Daily Living}

I. How did your use of substances affect your ability to care for yourself, such as bathing, grooming, dressing and eating?

2. How has substance use affected your sexual activities?

\section{Instrumental Activities of Daily Living}

I. How did substance use impacted on your ability to travel freely in your community?

2. What stigma did you face from the community/society, if any?

3. How did using substances impact your financial situation?

4. How has substance use impacted on your health?

5. Do you follow a particular religion? If so, how did substance use affected your religious observances and practices?

\section{Sleep and Rest}

I. How has substance use affected your quality of sleep and sleep patterns?

\section{Social Participation}

I. How did substance use impact on your relationships with your friends and family?

2. How did substance use impact on your ability to form intimate relationships?

3. Do others treat you differently because of your substance use?

\section{Work}

If participant is Unemployed:

I. How long have you been unemployed for and what are the reasons for this?

2. How many jobs have you had in the past, and why did you leave the jobs?

3. How has your use of substance use affected your ability to find and perform at a job?

4. If participant is Employed:

5. How many jobs have you had in the past and what were the reasons for leaving?
6. What work do you currently have and where?

7. What are your job tasks/duties?

8. What effect has your use of substance use had on your work?

\section{Leisure}

I. How did you spend your free time before substance abuse, during the period of use of substances and after rehabilitation?

2. How did your use of drugs affect your ability to perform your hobbies and activities of interests?

\section{Closure}

I. Do you think there is a need for gender sensitive substance abuse interventions for women specifically? Why or why not?

\section{REFERENCES}

I. Lal R, Deb KS, Kedia, S. Substance use in women: Current status and future directions. Indian J Psychiatry. 2015; 57(2). https://doi.org//0.4103/0019-5545.16149|

2. Tuchman E. Women and Addiction: The Importance of Gender Issues in Substance Abuse Research. Journal of Addictive Diseases. 2010; 29(2): 127-138. http://dx.doi.org//0.1080// 055088/003684582.

3. Peltzer K, Phaswana-Mafuya N. Drug use among youth and adults in a population-based survey in South Africa. S Afr J Psychiat. 2018;24(0), al I39.

https://doi. org//0.4102/sajpsychiatry. v24i0.1139

4. National Institute on Drug Abuse. Substance Use in Women. United States: National Institutes of Health; 2020. Available from: https://www.drugabuse.gov/publications/drugfacts/substance-usein-women . (2 May 20I8)

5. Greenfield SF, Back SE, Lawson K, Brady KT. Substance Abuse in Women. Psychiatric Clinics of North America. 20 I 0; 33(2): 339-355. https://doi.org/10.1016/j.psc.2010.01.004

6. Substance Abuse and Mental Health Services Administration. Substance Abuse Treatment: Addressing the Specific Needs of Women. Treatment Improvement Protocol (TIP). 2009; 51: 09-4426.

7. Van Willigen M. Multiple Roles and Women's Health. Wiley Online Library. 20 I4. https://doi.org/10.1002/978I I I84 I0868.wbehibs360

8. Stone M. Understanding the Impact of Substance Abuse on Occupation Using the Lifestyle History Questionnaire. Eastern Kentucky University: Occupational Therapy Doctorate Capstone Projects; 2017. Available from: https://encompass.eku.edu/cgi/viewcontent. cgi?article $=1030$ \&context $=$ otdcapstones. $(23$ February 2018)

9. Harvard Medical School. Addiction in Women. Harvard Medical School: Harvard Health Publishing; 2010. Available from: https://www.health.harvard.edu/newsletter_article/addiction-inwomen. (4 April 2018)

10. United Nations Office on Drugs and Crime. World Drug Report. New York: United Nations Publication; 2016. Available from: https://www.unodc.org/doc/wdr2016/WORLD_DRUG_REPORT_2016_web.pdf. (22 August 2018)

I I. Substance Abuse and Mental Health Services Administration. Mental Health \& Substance Use Disorders. 2019.

https://www.samhsa.gov/disorders/substance-use (22 August 2018)

12. American Psychiatric Association. Diagnostic and Statistical Manual of Mental Disorders. Fifth Edition. Arlington, WA: American Psychiatric Association; 2013.

13. Back SE, Payne RL, Wahlquist AH, Carter RE, Stroud Z, Haynes L, Hillhouse M, Brady KT, Ling W. Comparative Profiles of Men and Women with Opioid Dependence: Results from a National Multisite Effectiveness Trial. American Journal of Alcohol Abuse. 20I I; 37(5): 313-323. https://doi.org/10.3109/00952990.201।.596982 
14. Brady KT, Randall CL. Gender differences in substance use disorders. The Psychiatric clinics of North America. 1999; 22(2): 24I-252. https://doi.org/10.1016/s0193-953x(05)70074-5

15. Matuska KM, Christiansen $\mathrm{CH}$. A proposed model of lifestyle balance. Journal of Occupational Science. 2008; I5(I): 9-19. https://doi.org/I0.1080/I442759I.2008.9686602.

16. McBride AB. Mental Health Effects of Women's Multiple Roles. Addictions Nursing Network. 1990; 2(3): 4-I4.

17. Hecht LM. Role Conflict and Role Overload: Different Concepts, Different Consequences. Sociology Inquiry. 200I; 7I(I): III-I2I.

18. Andersson C, Eklund M, Sundh V, Thundal K, Spak F. Women's patterns of everyday occupations and alcohol consumption. Scandinavian Journal of Occupational Therapy. 2012; 19(3): 225-238. https://doi.org/10.3109/1 1038128.2010.527013

19. Goodell S, Druss BG, Reisinger Walker E. Mental Disorders and medical co-morbidity (The Synthesis Project, Policy brief No. 2.). Princeton, NJ: The Robert Wood Johnson Foundation; $20 \mathrm{II}$.

20. Horsfall J, Cleary M, Hunt GE, Walter G. Psychosocial Treatments for People with Co-occurring Severe Mental Illnesses and Substance Use Disorders (Dual Diagnosis): A Review of Empirical Evidence. Harvard Review of Psychiatry. 2009; 17(I): 24-34. https://doi.org/10.1080/10673220902724599

21. Anaby D, Jarus T, Backman CL, Zumbo BD. The role of occupational characteristics and occupational imbalance in explaining well-being. Applied Research in Quality of Life. 2010; 5(2): 81-104. https://doi.org//0.1007/s | |482-010-9094-6

22. Cash SJ, Wilke DJ. An Ecological Model of Maternal Substance Abuse and Child Neglect: Issues, Analyses, and Recommendations. American Journal of Orthopsychiatry. 2003; 73(4): 392-404. http://dx.doi.org/10.1037/0002-9432.73.4.392

23. Meyer JP, Springer SA, Altice FL. Substance Abuse, Violence, and HIV in Women: A Literature Review of the Syndemic. Journal of Women's Health. 20I I; 20(7), 99I-1006. https://doi.org/10.1089/jwh.2010.2328

24. Collins RL, Ellickson PL, Orlando M, Klein DJ. Isolating the nexus of substance use, violence and sex risk for HIV infection among young adults in the United States. AIDS Behaviour Journal. 2005; 9(I): 73-87. https://doi.org/I0.1007/s I046I-005-1683-2

25. Tross S, Campbell ANC, Cohen LR, Calsyn D, Pavlicova M, Miele G, Hu MC, Haynes L, Nugent N, Gan W, Hatch-Maillette M, Mandler R, McLaughlin P, El-Bassel N, Crits-Christoph P, Nunes EV. Effectiveness of HIV/STD Sexual Risk Reduction Groups for Women in Substance Abuse Treatment Programs: Results of a NIDA Clinical Trials Network Trial. Journal of Acquired Immune Deficiency Syndromes. 2009; 48(5): 58I-589.

https://doi.org/I0.1097/QAl.0b0 I 3e3 I8I7efb6e

26. Coovadia H, Jewkes R, Barron P, Sanders D, Mclntyre D. The health and health system of South Africa: historical roots of current public health challenges. Lancet. 2009; 374: 817-834. https://doi.org/10.1016/S0140-6736(09)6095I-X

27. Ghebremichael M, Paintsil E, Larsen U. Alcohol Abuse, Sexual Risk Behaviours and Sexually Transmitted Infections in Women in Moshi Urban District, Northern Tanzania. Sexually Transmitted Diseases. 2009; 36(2): 102-107. https://doi.org/10.1097/OLQ.0b0 13e31818b20e6

28. Cloete LG, Ramugondo EL. “I drink”: Mothers' alcohol consumption as both individualized and imposed occupation. South African Journal of Occupational Therapy. 2015; 45(I): 34-40. http://dx.doi. org/10.17159/2310-3833/2015/v45nola6

29. Jones HE, Browne FA, Myers BJ, Carney T, Middlesteadt Ellerson R, Kline TL, Poulton W, Zule WA, Wechsberg WM. Pregnant and
Nonpregnant Women in Cape Town, South Africa: Drug Use, Sexual Behaviour, and the Need for Comprehensive Services. International Journal of Paediatrics. 201 I. https://doi.org/10.1 I55/201 I/3534I0

30. National Institute on Drug Abuse. Prenatal exposure to drugs of abuse. 20I I. Available from http://www.drugabuse.gov/sites/default/ files/prenatal.pdf (27 October 2017)

31. Hanson RF, Self-Brown S, Fricker-Elhai AE, Kilpatrick DG, Saunders $B E$, Resnick HS. The relations between family environment and violence exposure among youth: Findings from the National Survey of Adolescents. Child Maltreatment. 2006; II (I): 3-I5.

32. Institute of Medicine and National Research Council. New directions in child abuse and neglect research. Washington, DC: The National Academies Press; 2013. Available from

http://www.iom.edu/ Reports/2013/New-Directions-in-Child-Abuseand- Neglect-Research.aspx. (27 October 2017)

33. Child Welfare Information Gateway. Parental substance use and the child welfare system [Internet]. Washington, DC: U.S. Department of Health and Human Services, Children's Bureau; 20I4. Available from: https://www.childwelfare.gov/pubs/factsheets/parentalsubabuse/ (8 May 2018)

34. Chaplin TM, Sinha R. (20/3). Stress and parental addiction. In: Parenting and Substance Abuse: Developmental Approaches to Intervention. Suchman NE, Pajulo M, Mayes LC, editors. New York: Oxford University Press. 2013: 3-23.

35. Andersson C, Eklund M, Sundh V, Thundal K, Spak F. Women's patterns of everyday occupations and alcohol consumption. Scandinavian Journal of Occupational Therapy. 2012; 19(3): 225-238. DOI: $10.3109 / 11038128.2010 .527013$

36. Frese, M. Cultural Practices, Norms, and Values. Journal of CrossCultural Psychology. 20I5; 46(10): I327-1330. https://doi.org/I0.1 I 77/0022022II5600267.

37. Michalak L., Trocki K., Katz, K. "I am a Muslim and My Dad is an Alcoholic - What Should I Do?": Internet-Based Advice for Muslims about Alcohol. Journal of Muslim Mental Health. 2009; 4(I): 47-66. https://doi.org/I0.1080/1556490090277/325

38. Creswell, J.W. Qualitative Enquiry and Research Design: Choosing Among Five Approaches. 2007. 2nd Ed. London, UK: Sage Publications.

39. The American Association of Occupational Therapy. Occupational Therapy Practice Framework: Domain and Process 3rd Edition. The American Journal of Occupational Therapy. 2014; 68(Supplement I): SI-S48.

40. Braun V, Clarke V. Using thematic analysis in psychology. Qualitative research in psychology. 2006 Jan I; 3(2): 77-I0I.

4I. Dube SR, Anda RF, Felitti VJ, Croft JB, Edwards VJ, Giles WH. Growing up with parental alcohol abuse: Exposure to childhood abuse, neglect, and household dysfunction. Child Abuse \& Neglect. 200 I; 25: 1627-1640.

42. Staton-Tindall M, Sprang G, Clark J, Walker R, Craig C. Caregiver substance use and child outcomes: A systematic review. Journal of Social Work Practice in the Addictions. 2013; 13(1): 6-31. https://doi.org/I0.1080/I533256X.2013.752272

43. Bold KW, Epstein EE, McCrady BS. Baseline health status and quality of life after alcohol treatment for women with alcohol dependence. Addictive Behaviours: An International Journal. 2017; 64: 35-4I. https://doi.org/10.1016/j.addbeh.2016.08.014

44. Schafer, G. Family functioning in families with alcohol and other drug addiction. 201 I. Available from https://www.msd.govt.nz/aboutmsd-and-our-work/publications-resources/journals-and-magazines/ social-policy-journal/spj37/37-family-functioning-in-families-withalcohol-and-other-drug-addiction.html. (4 June 2018)

45. Sarkar S, Patra B, Kattimani S. Substance use disorder and the family: 
An Indian perspective. Medical Journal of Dr. D.Y. Patil University. 2016; 9(I): 7. https://doi.org/10.4103/0975-2870.1724I3

46. Radebe, N. Exploring the effects of substance abuse on the family in a selected eThekwini District. 2015. Available from http://ukzn-dspace.ukzn.ac.za/handle/I04I3/I44I3 (4 June 2018)

47. Sorsdahl K, Stein DJ, Lund C. Mental Health Services in South Africa: Scaling up and future directions. African Journal of Psychiatry. 2012; I5: |68-I7|. https://doi.org/I0.43 |4/ajpsy.v15i3.2I

48. Elms N, Link K, Newman A, Brogly SB. Need for women-centered treatment for substance use disorders: results from focus group discussions. Harm Reduction Journal. 2018; I5(I): 40.

https://doi.org/I0.1 I86/s I2954-018-0247-5

49. Christiansen $C$, Townsend EA. Introduction to occupation: the art and science of living. 2nd Ed. Upper Saddle River, NJ: Pearson Education; 2010.

50. Brady KT, Grice DE, Dustan L, Randall C. Gender differences in substance use disorders. The American Journal of Psychiatry. 1993; I50(II): 1707-I7II. https://doi.org/10.1 I76/ajp.150.1I.1707

5I. Buvik K, Elin KB, Gripenberg J. Alcohol and drug use among staff at licensed premises in Norway. Scandinavian Journal of Public Health. 2018; 47(4): 393-399. https://doi.org//0.1 I77//4034948/876/4I7

52. Hood, C. The Risk Game and the Blame Game. Government and Opposition. 2002; 37(1): 15-37. https://doi.org/10.1 I I I/1477-7053.00085

53. Substance Abuse and Mental Health Services Administration (SAMHSA). Results from the 201 I National Survey on Drug Use and Health: Mental Health Findings, NSDUH Series H-45, HHS Publication No. (SMA) 12-4725. Rockville, MD: Substance Abuse and Mental Health Services Administration, 2012. http://store.samhsa. gov/home.

54. Pagano ME, Phillips KA, Stout RL, Menard W, Piliavin JA. Impact of helping behaviors on the course of substance-use disorders in individuals with body dysmorphic disorder. Journal of studies on alcohol and drugs. 2007; 68(2): 29I-295.

https://doi.org//0.15288/jsad.2007.68.29।

55. Al-Omari H, Hamed R, Abu Tariah H. The Role of Religion in the Recovery from Alcohol and Substance Abuse Among Jordanian Adult. Journal of Religion and Health. 20I5; 54(4): I268-I 277. https://doi.org/10.1007/sI0943-014-9868-5

56. Walton-Moss B, Ray EM, Woodruff K. Relationship of Spirituality or Religion to Recovery from Substance Abuse. Journal of Addictions Nursing. 2013; 24(4): 217-226.

https://doi.org/10.1097/jan.000000000000000 I

\section{Corresponding Author}

*Humayra Rawat

Email: humayra.rawat@gmail.com 